\title{
Massive Traumatic Subcutaneous Emphysema
}

\author{
Diana Fernandes*, Sara Pereira, Celeste Guedes, David Silva
}

\begin{abstract}
74 year-old-man, former smoker, with chronic obstructive pulmonary disease GOLD grade 4, group D, with emphysema component, treated in a pulmonary rehabilitation program, on oxygen therapy and nocturnal bi-level positive airway pressure (BiPAP) ventilation. During the night he had a traumatic rib fracture (5-11th right ribs) but still he used BiPAP ventilation during the sleep. In the morning after he presented with a diffuse and massive emphysema in the face, thorax and abdominal regions. On physical examination, the patient presented with massive swelling and crepitus on palpation. A chest computed tomography (CT) scan confirmed a diffuse subcutaneous emphysema and revealed a mediastinal emphysema and bilateral small pneumothorax. A fast resolution of the emphysema was of paramount importance as the patient was severely agitated due to his inability to open both eyes, and the need to reintroduce BiPAP ventilation as soon as possible. It was placed a fenestrated subcutaneous catheter on left hemithorax and a subcutaneous ostomy on right hemithorax for comparative purpose. It was also performed a confluent centripetal massage towards drainage orifices, with immediate and substantial improvement of emphysema, especially in left hemithorax, and progressive ocular opening. Further emphysema absorption occurred during hospitalization.
\end{abstract}

\section{KEYWORDS}

chronic obstructive pulmonary disease; extensive subcutaneous emphysema; venous catheter; pneumomediastinum; subcutaneous emphysema

\section{AUTHOR AFFILIATIONS}

Department of Internal Medicine, Centro Hospitalar Médio Ave, Vila Nova de Famalicão, Portugal

* Corresponding author: Diana Fernandes, Department of Internal Medicine, Centro Hospitalar Médio Ave, Rua Cupertino de Miranda, 4761-917, Vila Nova de Famalicão, Portugal; e-mail: diana.silva.fer@gmail.com

Received: 1 July 2019

Accepted: 6 July 2020

Published online: 22 December 2020

Acta Medica (Hradec Králové) 2020; 63(4): 194-197

https://doi.org/10.14712/18059694.2020.63

(c) 2020 The Authors. This is an open-access article distributed under the terms of the Creative Commons Attribution License (http://creativecommons.org/licenses/by/4.0), which permits unrestricted use, distribution, and reproduction in any medium, provided the original author and source are credited. 


\section{INTRODUCTION}

Subcutaneous emphysema is often nothing more serious than a cosmetic problem $(1,2)$. Although it can be extremely uncomfortable for the patient, even when it is severe, subcutaneous emphysema rarely has pathophysiologic consequences $(1,2)$. The widely employed methods of therapy, which include placing chest tubes or lacerating the skin on the anterior chest, are time-consuming and uncomfortable $(1,2)$.

Here, we report a case of extensive subcutaneous emphysema following trauma, treated with an easily constructed fenestrated venous catheter.

\section{CASE REPORT}

We report a case of a 74-year-old man admitted to the hospital with extensive subcutaneous emphysema. He had a history of chronic obstructive pulmonary disease GOLD grade 4 , group D, with emphysema component, treated in a pulmonary rehabilitation program, on oxygen therapy and nocturnal bi-level positive airway pressure (BiPAP) ventilation. Other past medical history included arterial hypertension, dyslipidemia, epilepsy and was a former smoker.

He had a traumatic rib fracture (5-11th right ribs) during the night after falling from his own height and hitting the ground with his right hemithorax region. After that he went to sleep maintaining BiPAP ventilation until morning. In the morning after, he was admitted at emergency room with a diffuse and massive emphysema on his face, thorax and abdominal regions.

On physical examination, the patient presented a massive swelling and crepitation on palpation. His blood pressure was $107 / 83 \mathrm{mmHg}$, pulse rate of $100 / \mathrm{min}$ and regular, SpO2 100\% with FiO2 100\% and axillary temperature of $36^{\circ} \mathrm{C}$. Pulmonary and cardiac auscultation were difficult to assess due to massive emphysema.
Arterial blood gas analysis revealed type II respiratory failure; and electrocardiogram showed sinus rhythm, with global low voltage. Complete blood count, liver and renal function tests were normal. Chest computed tomography scan confirmed a diffuse subcutaneous emphysema and showed mediastinal emphysema and bilateral small pneumothorax (Figure 1).

He was transferred to the intermediate care unit for clinical surveillance and close monitoring.

A fast resolution of the emphysema was required as the patient was severely agitated due to bilateral ocular opening impairment and the need to reintroduce BiPAP ventilation as soon as possible. Hence, under local anesthesia and antiseptic measures, a Redon catheter (12 French, B.Braun) was inserted on left hemithorax, insertion point located 4th next to left side of sternum. The catheter was placed using the Seldinger's technique: the subcutaneous left hemithorax was punctured through a blunt dissection with a sharp hollow needle; a guidewire is then advanced through the lumen of the needle, and the needle is withdrawn; finally the catheter was insert and the guidewire was withdrawn. Then, it was fixed to the skin with $2 / 0$ silk and adapted to drain bags. On the right hemithorax, a subcutaneous ostomy with about $1 \mathrm{~cm}$, was performed for comparative purpose (Figure 2).

Afterwards, it was performed a compressive massage in a centripetal fashion, towards drainage orifices, with immediate improvement of emphysema. This had led to a significant improvement with progressive ocular opening over the next hour. Conservative treatment with oxygen and inhalers were continued. The swelling decreased substantially and BiPAP ventilation was discontinued on the basis of the results of arterial blood gas analysis and following case discussion with pulmonology team. During the stay at intermediated care unit, the patient developed a nosocomial pneumonia managed with empirical antibiotic therapy - piperacillin-tazobactam. No other major intercurrence was described.
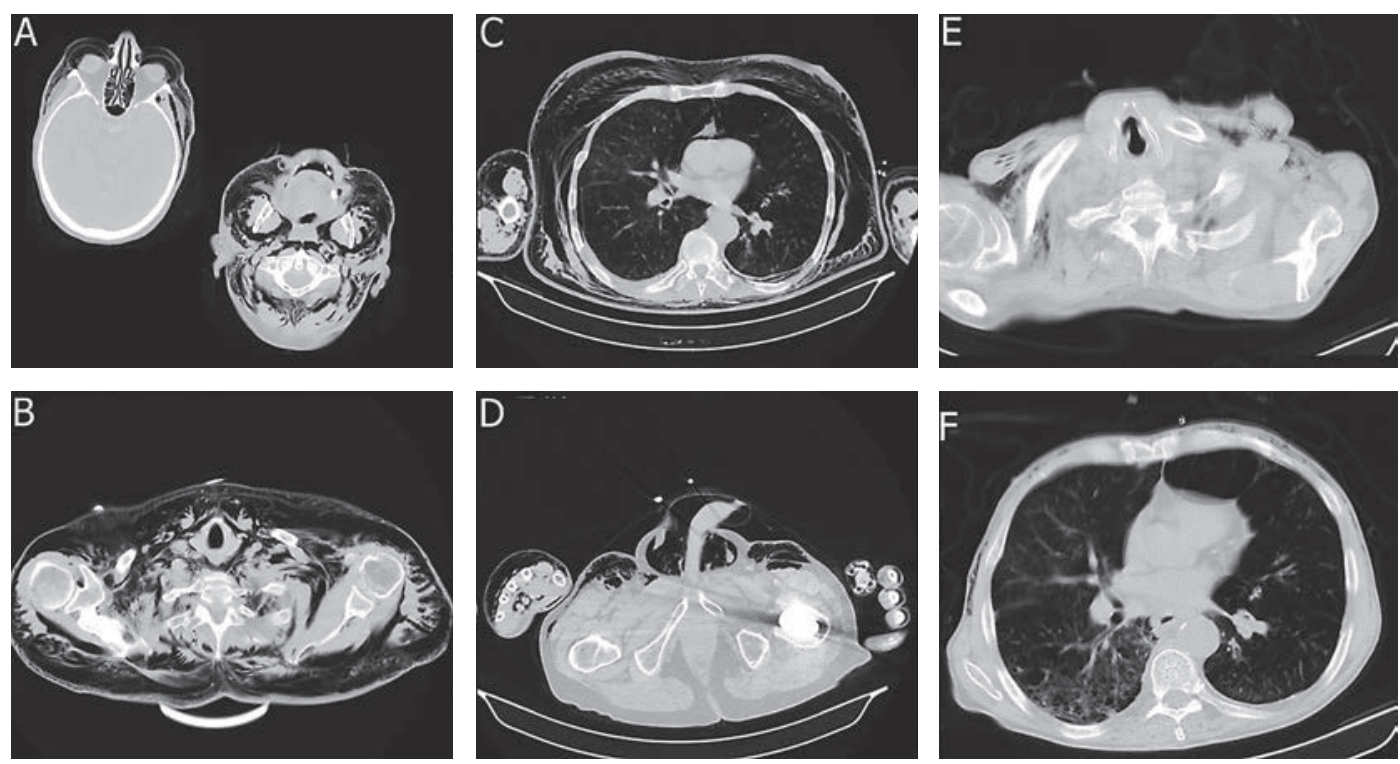

Fig. 1 Computed tomography scans showing diffuse subcutaneous emphysema, mediastinal emphysema and bilateral small pneumothorax. 


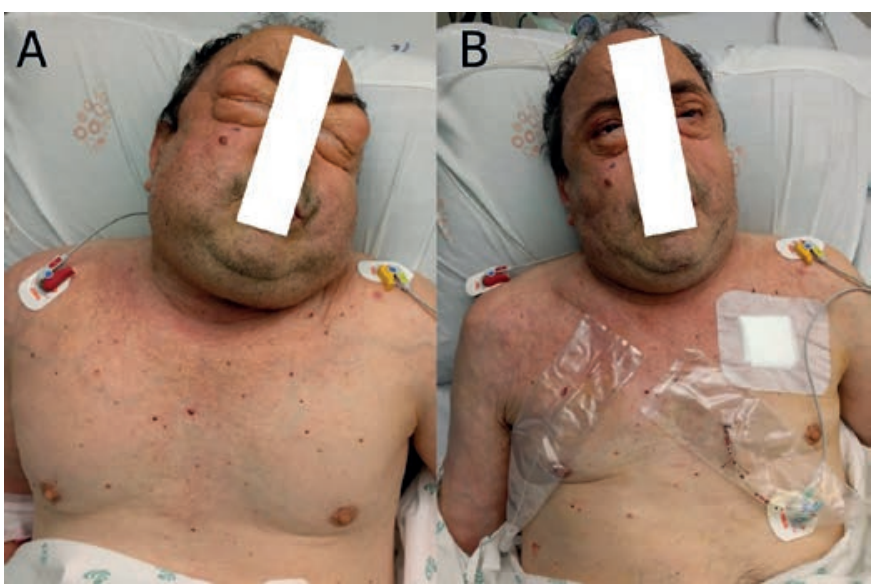

Fig. 2 In figure A the patient shows an exuberant emphysema. In figure $B$ the fenestrated subcutaneous venous catheter ( 12 French) was inserted on left hemithorax, and subcutaneous ostomy, with about $1 \mathrm{~cm}$ on right hemithorax was performed. In figure B the patient shows a important decrease of emphysema one day after the procedures.

Patient was transferred from intermediated care unit to medical ward at day 5 , after further emphysema absorption.

The subcutaneous venous catheter was removed without any signs of inflammatory reaction 9 days later. The treatment for nosocomial pneumonia was completed. The patient was discharged home with complete symptoms resolution.

\section{DISCUSSION}

Aberrant extra-alveolar air starts with alveolar rupture and leakage of air into the pulmonary interstitium (3-5). This air subsequently tracks along the perivascular space to the mediastinum, a phenomenon known as the Macklin effect (3-5). Further extension along tissue planes leads to subcutaneous emphysema, pneumopericardium and pneumoperitoneum (3-5). This pathophysiologic process, first described by Macklin in 1939, is summed up in three steps: alveolar ruptures, air dissection along bronchovascular sheaths, and spreading of this pulmonary interstitial emphysema into the mediastinum (3-5). When leakage of air is greater than reabsorption, progressive accumulation in various tissue planes occurs (3-5). Commonly, the least resistance to expansion is offered by subcutaneous tissue, leading to worsening subcutaneous emphysema (SE) (3-5).

Subcutaneous emphysema often presents a therapeutic dilemma $(1,2)$. Patients with severe SE may develop dysphagia or vision problems because of periorbital swelling, just like in this case $(1,2)$. More severe complications have been rarely reported, which include respiratory failure, pacemaker malfunction, airway compromise, and tension phenomena $(1,2)$.

A number of techniques have been employed to treat subcutaneous emphysema (2, 6-10). These include infraclavicular incisions, placement of additional chest tubes either in the intrapleural space or subcutaneously, tracheostomy, and large-bore subcutaneous drains with or without suction (2, 6-10). In this patient two techniques were used: on the right side an infraclavicular incision was performed and on the left side a subcutaneous catheter was placed. The latter equipment is widely available and easily modified, minimally invasive, it is simple to insert, maintain and is effective, painless, does not require suction, and is less likely to produce a scar $(2,6-10)$. We have not found any significant difference between the two techniques used in this patient, but we consider infraclavicular incision to be a best suited technique due to its simplicity and associated with a lesser risk of infection.

A key step in this process is to increase the interstitial hydrostatic pressure by sequential massage from the face downwards and arm upwards towards the catheter, that should be done 3 to 4 times per day (6). The resolution of emphysema after the catheter placement started only after the above step (6).

To confirm the adequacy of the compressive massage, Srinivas $R$ et al. suggested the placement of an underwater trap and visualization of bubbling as endpoints for adequate compressive massage (6).

Suri JC, Ray A et al., reported in a case report that resolution of swelling was noticed after 8 hours and the catheter was removed after 24 hours (2). According to these authors, this technique ensured an earlier resolution compared to previous reports (where the median time of improvement was 3.7 days) (2). This can be attributed to clear identification of goal to be attained by compressive massages or the sealing of air-leak concurrent to catheter insertion. Other ancillary adjuncts like adequate analgesia, cough suppression and supplemental oxygen therapy may have hastened recovery (2). In the timing of resolution, we should take in account the presence of other mechanism that could perpetuate the emphysema, as for example an ongoing leak of air or significant lung collapse. In these cases, the closure of a fistula or treatment of pneumothorax with thoracic drains should be also applied. Although no studies have yet documented for how long the catheter works, Leo $\mathrm{F}$ et al. defends no longer than 3 days (9). Usually, at the time of removal, the catheter is obstructed by clots and dislodged by the movements of the subcutaneous and muscular planes (9).

In the present case a significant reduction of emphysema was noted after the first massage, so we_believe that the first massage done with repetitive and vigorous movements is essential for the recovery.

Although we have not experienced any problems with the catheter described here, there are two potential problems (1-2). The first one is infection but, as long as a rigorous asepsis is maintained during placement of the catheter, it is not higher than the risk of infection for central venous catheters (9); and the second is that the catheter may become blocked with blood (1-2).

In conclusion, extensive subcutaneous emphysema can be associated with extreme discomfort, anxiety, longer hospital stays and respiratory failure. Fenestrated catheters are simple to insert and maintain, and the procedure is effective, painless, minimally invasive and infrequently complicated by infection. We did not find any difference between this technique and infraclavicular incision, but we defend the use of infraclavicular incision because it is 
easier to perform, less expensive, and associated with a lower number of infections. The key step is to increase the interstitial hydrostatic pressure by sequential massage.

\section{REFERENCES}

1. Beck PL, Heitman SJ, Mody CH. Simple Construction of a Subcutaneous Catheter for Treatment of Severe Subcutaneous Emphysema. CHEST 2002; 121: 647-9.

2. Suri JC, Ray A, Khanna A, Chitte NS. A novel treatment modality for extensive subcutaneous emphysema. J Postgrad Med 2014; 60(2): 217-8.

3. Macklin CC. Transport of air along sheaths of pulmonic blood vessels from alveoli to mediastinum: clinical implications. Arch Intern Med 1939; 64: 913-2.

4. Wintermark M, Schnyder P. The Macklin Effect a Frequent Etiology for Pneumomediastinum in Severe Blunt Chest Trauma. CHEST 2001; 120: 543-7.
5. Mason RJ, Murray JF, Broaddus VC, Nadel JA. Mediastinal disorders. In: Murray JF, Nadel JA, eds. Murray and Nadel's Textbook of Respiratory Medicine. 4th ed. Philadelphia: Elsevier Saunders, 2005: 2039-49.

6. Cesario A, Margaritora S, Porziella V, Granone P. Microdrainage via open technique in severe subcutaneous emphysema. Chest 2003; 123: 2161-2.

7. Srinivas R, Singh N, Agarwal R, Agarwal AN. Management of extensive subcutaneous emphysema and pneumomediastinum by micro-drainage: Time for a re-think? Singapore Med J 2007; 48: e323-6.

8. Sucena M, Coelho F, Almeida T et al. Enfisema subcutâneo maciço - Tratamento com drenos subcutâneos. Revista Portuguesa de Pneumologia 2010; 16(2): 321-9.

9. Leo F, Solli P, Veronesi G, et al. Efficacy of Microdrainage in Severe Subcutaneous Emphysema. In Communications to the Editor. Chest 2002; $122(4): 1498-9$.

10. Ozdogan M, Gurer A, Gokakin AK, et al. Treatment of severe subcutaneous emphysema by fenestrated angiocatheter. Intensive Care Med 2005; 31: 168 . 